Aline Abdu

\title{
Estudo Numérico dos Modelos de Combustão Existentes no Software CFX-5.7.1
}

Projeto de Graduação

DEPARTAMENTO DE ENGENHARIA MECÂNICA Projeto Final de Graduação em

Engenharia Mecânica 


\section{Pontifícia Universidade C $_{\text {Atólica }}$ DO RIO DE JANEIRO}

Aline Abdu

Estudo Numérico dos Modelos de Combustão Existentes no Software CFX-5.7.1

Projeto de Graduação

Trabalho apresentado ao final do curso de Engenharia Mecânica do Departamento de Engenharia Mecânica da PUC-Rio como parte dos requisitos necessários para a finalização do curso de Engenharia Mecânica

Orientador: Prof. Luís Fernando Figueira da Silva 


\section{Agradecimentos}

Aos meus pais que com todo o amor, apoio e compreensão contribuiram para a conclusão deste trabalho.

Aos amigos que jamais esquecerei.

Ao meu orientador pela orientação e conhecimentos transmitidos. 


\title{
Resumo
}

\begin{abstract}
Abdu, Aline; ; Silva,Luís Fernando Figueira da. Estudo Numérico dos Modelos de Combustão Existentes no Software CFX-5.7.1. Rio de Janeiro, 2005. 32p. Projeto de Graduação - Departamento de Engenharia Mecânica, Pontifícia Universidade Católica do Rio de Janeiro.
\end{abstract}

Neste trabalho é realizado um estudo sobre os modelos de combustão existentes no software CFX-5.7.1 em um escoamento de canal, para combustão prémisturada. Para isto buscou-se selecionar um problema de geometria simples, porém representativo e que possuísse bons resultados experimentais.

Considera-se um escoamento turbulento de propano e de ar no qual a combustão é estabilizada a jusante de um obstáculo. Foram realizadas simulações em um escoamento inerte e reativo com diferentes modelos de combustão, isto é, $E d d y$ Dissipation e Finite Rate Chemistry. Também foi avaliado o efeito da escolha do método de discretização espacial sobre os resultados obtidos. O modelo de turbulência utilizado é o $k-\varepsilon$.

Um bom acordo entre resultados numéricos e experimentais foi obtido nos casos inertes e reativos para a velocidade longitudinal do escoamento e para o comprimento médio da região de recirculação presente a jusante do obstáculo. A velocidade transversal calculada apresentou discrepâncias com relação aos valores experimentais.

\section{Palavras-chave}

combustão, turbulência, modelagem numérica 


\section{Abstract}

Abdu, Aline; ; Silva,Luís Fernando Figueira da. I. Rio de Janeiro, 2005. 32p. Graduation Project - Departamento de Engenharia Mecânica, Pontifícia Universidade Católica do Rio de Janeiro.

$\mathrm{n}$ this work a study on the existing combustion models in CFX-5.7.1 software has been performed. The selected problem was the combustion within a channel. This simple geometry is representative of pratical problems and detailed experimental results are avaliable.

A turbulent flow of air and propane is considered in which the combustion is stabilized by an obstacle. Simulations in an inert and reactive flows has been performed using the Eddy Dissipation and Finite Rate Chemistry models.

The turbulence model used was $k-\varepsilon$. A good agreement between numerical and experimental results was obtained in the inert and reactive cases for the longitudinal speed of the flow and for the average length of the recirculation zone near the obstacle. The calculated transversal velocity presented discrepancies with relation to the experimental values.

\section{Keywords}

combustion, turbulence, numerical modelling 


\section{Conteúdo}

\begin{tabular}{lll}
\hline 1 & Introdução & 7
\end{tabular}

2 Metodologia 11

$\begin{array}{lll}2.1 & \text { Equações Governantes } & 11\end{array}$

$\begin{array}{lll}2.2 & \text { Modelos de Combustão } & 12\end{array}$

2.3 Condições de Contorno 13

$\begin{array}{llr}3 & \text { Resultados e Discussões } & 15\end{array}$

$\begin{array}{lll}3.1 & \text { Condições de Cálculo } & 15\end{array}$

\begin{tabular}{lll}
\hline 3.2 & Malhas Computacionais & 15
\end{tabular}

$\begin{array}{lll}3.3 & \text { Estrutura do Escoamento Inerte } & 17\end{array}$

$\begin{array}{lll}3.4 & \text { Estrutura do Escoamento Reativo } & 17\end{array}$

3.5 Comparação com Resultado Experimental 19

3.6 Gráficos de Convergência dos Casos Simulados 21

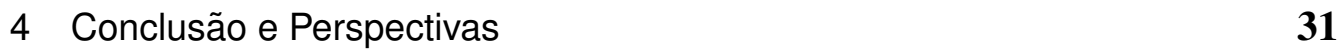

\begin{tabular}{ll}
\hline Referências Bibliográficas & 32
\end{tabular} 


\section{Lista de Figuras}

\begin{tabular}{lll}
\hline 1.1 & Chama de uma vela. & 7
\end{tabular}

1.2 Chama estabilizado sobre um bico de Bunsen. 8

1.3 Exemplos de chama turbulenta 3 . 9

\begin{tabular}{lll}
\hline 1.4 & Esquema do funcionamento de um ramiet. & 9
\end{tabular}

\begin{tabular}{lll}
1.5 & Esquema do queimador utilizado por Bedàt e Cheng 1. & 10 \\
\hline 1.6
\end{tabular}

1.6 Esquema do experimento do canal estudado por Sanquer el al. [2]. 10

2.1 Condições de contorno para o caso do canal com obstáculo. 13

2.2 Condições de contorno para o caso do queimador. 14

3.1 ESquema do domínio de cálculo e suas dimensãoes. 16

3.2 Malha hexaédrica próxima ao obstáculo. 16

$\begin{array}{lll}3.3 & \text { Vetores velocidades para o caso inerte i1. } & 17\end{array}$

3.4 Energia cinética da turbulência para o caso inerte i1. 18

3.5 Energia cinética da turbulência para o caso inerte i3. 19

3.6 Vetores velocidade para o caso reativo $r 1$.

3.7 Distribuição de temperatura ao longo do canal, caso r1. 21

3.8 Distribuição de temperatura na entrada do canal para o modelo de combustão Eddy Dissipation. 22

\begin{tabular}{lll}
\hline 3.9 & Distribuição de temperatura no canal para o modelo de com- & \\
bustão Finite Rate Chemistry. & 23
\end{tabular}

3.10 Evolução longitudinal da velocidade para os casos inertes. 24

3.11 Evolução longitudinal da velocidade para os casos inertes experimental. 24

3.12 Evolução longitudinal da velocidade para o caso reativo. 25

\begin{tabular}{|ll|}
\hline 3.13 Evolução longitudinal da velocidade para o caso reativo experi- & \\
\hline mental. & 25
\end{tabular}

3.14 Gráfico com a evolução longitudinal para os casos inertes. 26

3.15 Gráfico com a evolução longitudinal para os casos inertes experimental.

3.16 Evolução da velocidade transversal $v$ inerte. 27

3.17 Evolução da velocidade transversal $v$ inerte experimental. 27

3.18 Evolução da velocidade transversal $v$ reativo. 28

3.19 Evolução da velocidade transversal $v$ reativo experimental. 28

3.20 Gráfico de convergência do caso i1. 29

3.21 Gráfico de convergência do caso i3. 29

3.22 Gráfico de convergência do caso r1. 29

3.23 Gráfico de convergência do caso r3. 30 


\section{Introdução}

Combustão é um processo de oxidação rápida auto sustentada, acompanhada da liberação de luz e calor. Para que ocorra combustão é necessário que estejam em contato combustível e comburente, e uma fonte de energia e que estes reajam quimicamente. Esta fonte de energia é necessário para iniciar o processo de combustão, e deve fornecer uma energia mínima necessária à mistura para que a combustão ocorra de forma auto sustentável. Essa fonte de energia pode ser uma chama piloto, uma superfície aquecida, ou fagulhas, centelhas e raios. Em algumas situações o processo de combustão pode ocorrer em escoa-

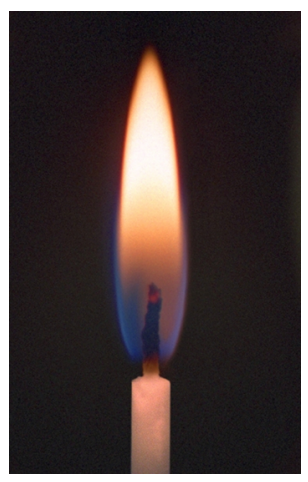

Figura 1.1: Chama de uma vela.

mentos laminares. Um exemplo de uma chama deste tipo é a chama de uma vela, como mostra a Fig.1. Neste caso o oxidante (ar) e o combustível (parafina) são separados pela superfície da chama. Uma outra situação limite possível, no que diz respeito ao grau de mistura entre combustível e oxidante, é a que ocorre nas chamas pré-misturadas. Nestas, a propagação da combustão ocorre dos gases frescos para os gases queimados, tendo como exemplo a chama estabilizada sobre um bico de Bunsen. Este tipo de chama é denominada pré-misturada. Quando o processo de combustão ocorre em escoamentos turbulentos, também é usual classificar as chamas segundo o grau de pré-mistura entre o combustível e o oxidante. A Fig 1.2 apresenta uma chama estabilizada sobre um bico de bunsen. 


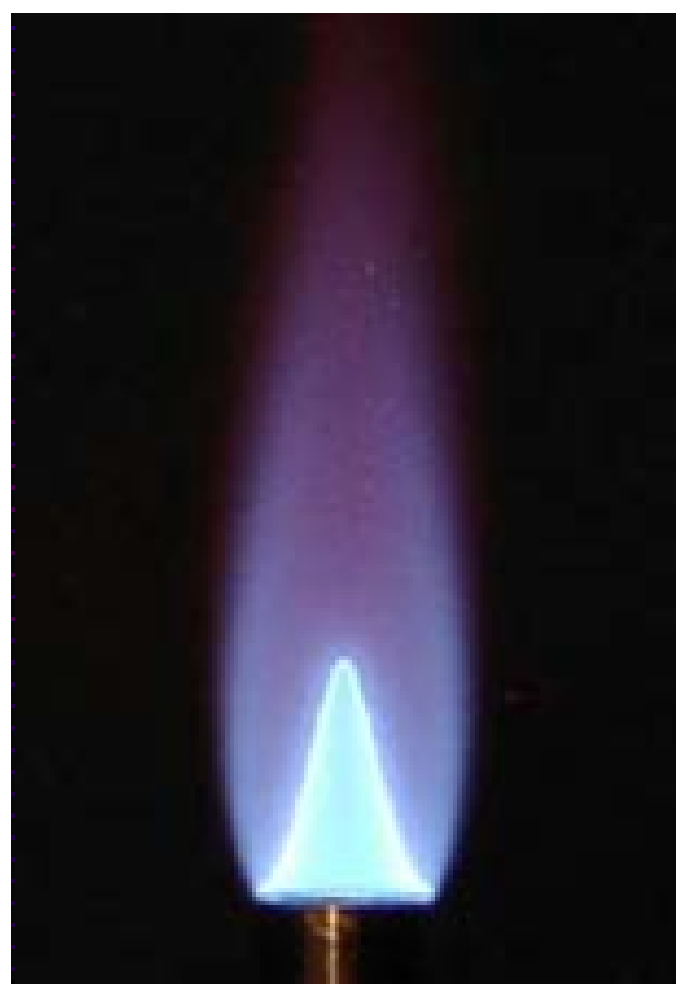

Figura 1.2: Chama estabilizado sobre um bico de Bunsen.

A Fig. 1.3 apresenta exemplos de chamas turbulentas estabilizadas entre um jato de gás natural de ar. Este tipo de situação é representativo do processo de combustão em turbinas a gás.

Neste trabalho será estudada numericamente, utilizando-se o programa de cálculo CFX 5.7.1, a combustão em escoamento turbulento no caso em que o combustível e o oxidante encontram-se pré-misturados. Esta situação é encontrada, por exemplo, em motores alternativos funcionando no ciclo Otto ou em queimadores de turbinas a gás, estato-jatos (ramjets). Este estudo numérico envolve a modelagem da combustão em escoamentos turbulentos em casos geometricamente simples, porém representativos destes sistemas práticos nos quais os escoamentos podem ser considerados como bidimensionais e estacionários.

Além disto, foram escolhidos na literatura resultados experimentais suficientemente detalhados, tanto no que se refere as condições de contorno quanto às medidas realizadas das quantidades turbulentas.

Com base nestes critérios, a pesquisa bibliográfica realizada permitiu selecionar dois experimentos candidatos envolvendo chamas turbulentas em escoamentos pré-misturados (i)chama turbulenta se propagando em um escoamento de turbulência intensamente isotrópica e (ii)chama pré-misturada estabilizada por um corpo de geometria triangular.

No primeiro caso, trata-se de chamas turbulentas propagando-se em um 

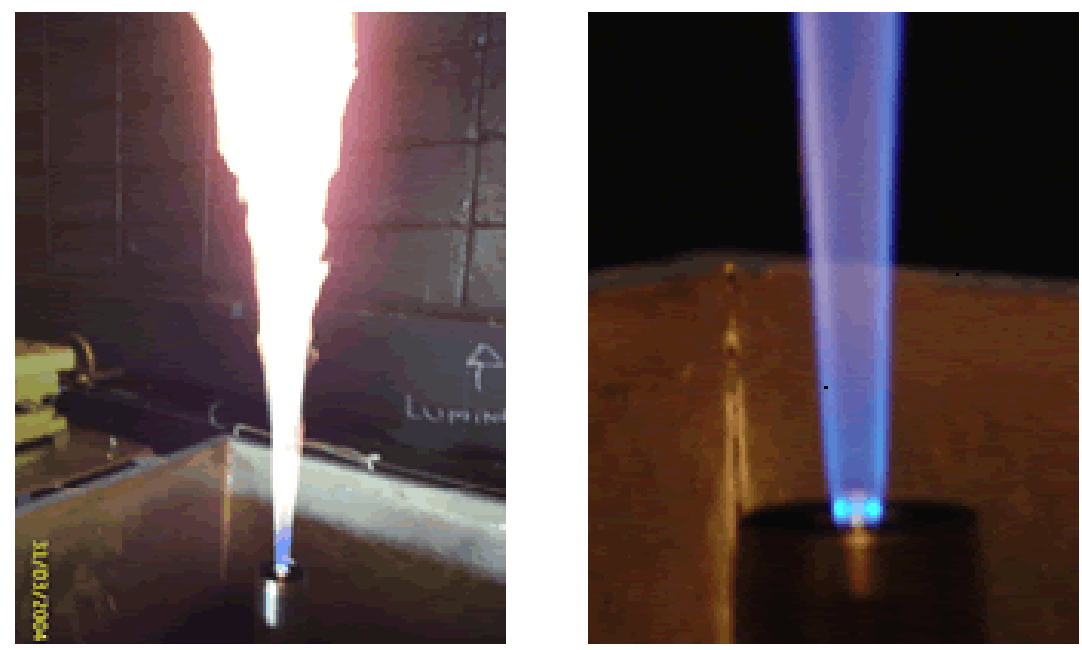

Figura 1.3: Exemplos de chama turbulenta 3 .

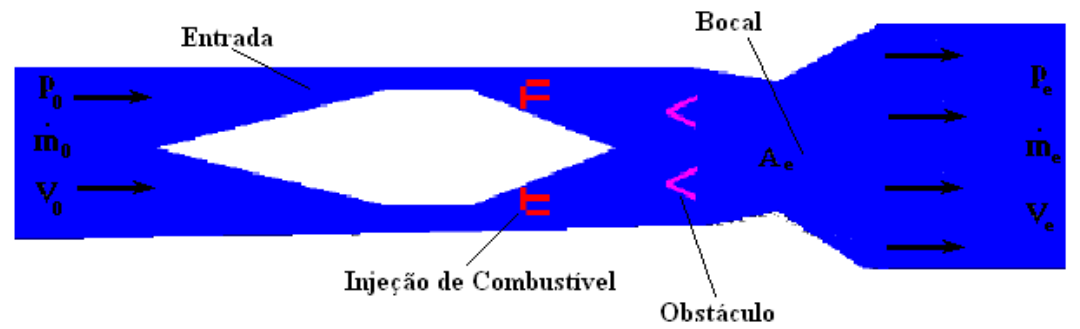

Figura 1.4: Esquema do funcionamento de um ramjet.

escoamento de turbulência intensa e quase isotrópica, gerada em um queimador do tipo swirl 1]. Esta configuração resulta em chamas pré-misturadas estáveis, possibilitando assim o estudo de diversas condições de escoamento, e em particular de diferentes intensidades da turbulência a montante da chama. Um esquema desse queimador é apresentado na Fig.1.5. Este queimador consiste em um gerador de turbulência acoplado a um bocal convergente e um tubo de 50 $\mathrm{mm}$ de diâmetro e $233 \mathrm{~mm}$ de comprimento onde o swiler está conectado. Após a injeção, a mistura $\mathrm{CH}_{4}$ /ar passa pelo gerador de turbulencia antes de entrar no bocal convergente. Note-se que o swirl é gerado por injeção de ar no tubo, a 103 mm da saída deste. As chamas são estabilizadas a jusante da saída do tubo, no escoamento divergente que é formado quando a mistura deixa o tubo.

O segundo caso envolve o estudo da chama pré-misturada estabilizada a jusante de um obstáculo que possui a forma de prisma de base triangular [2]. Esta experiência foi construída pensando-se especificamente em facilitar a realização de simulações numéricas, possuindo condições de contorno bem 


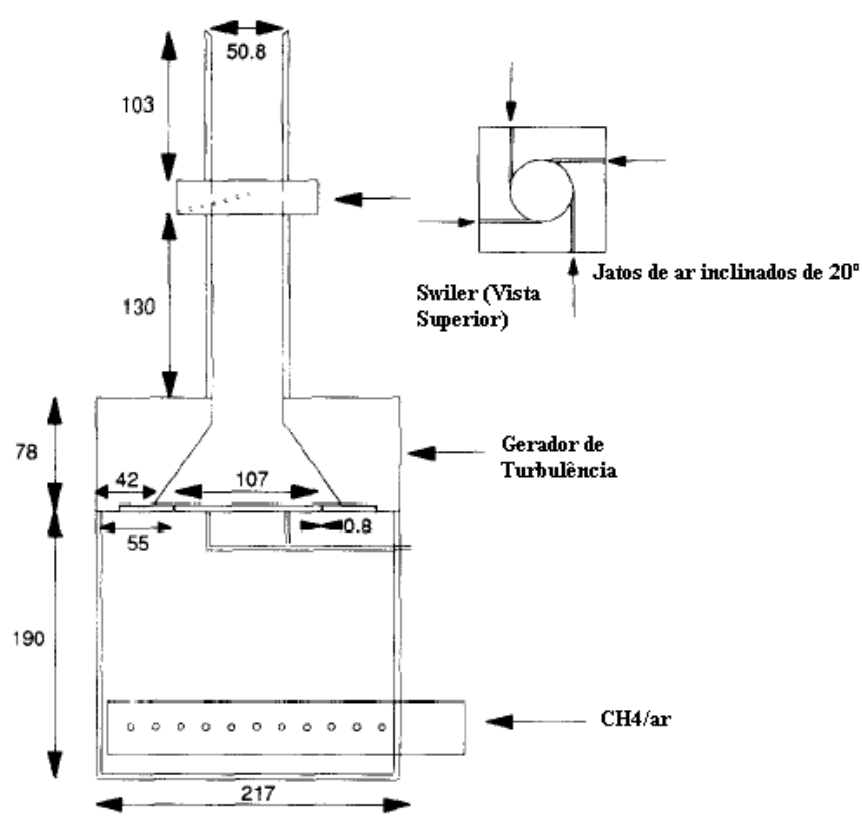

Figura 1.5: Esquema do queimador utilizado por Bedàt e Cheng 1 .

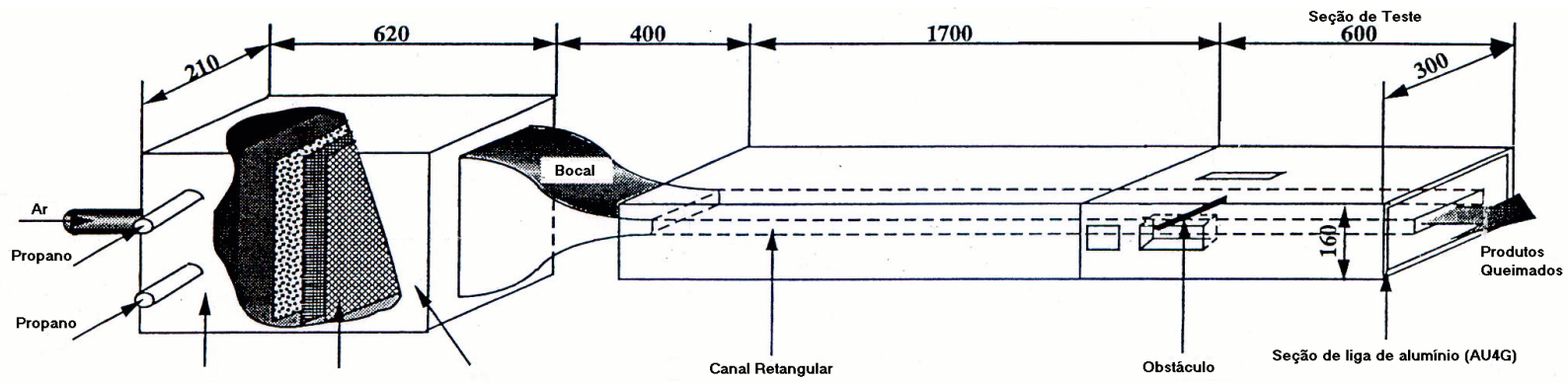

Figura 1.6: Esquema do experimento do canal estudado por Sanquer el al. 2].

definidas. O esquema deste experimento pode ser observado na Fig 1.6. A seção de teste consiste em um canal de $2,3 \mathrm{~m}$ de comprimento que possui um seção retangular constante de $160 \times 28,8 \mathrm{~mm}^{2}$ construída com tijolos refratários. O obstáculo está montado no centro do canal a distância de 1.86 m da entrada. Os resultados disponíveis para este experimento são baseados na medição de velocidade utilizando Velocimetria Laser Doppler.

Serão estudados neste trabalho dois casos de escoamento quimicamente inerte e dois casos reativos para uma mistura pobre de propano e de ar.

Comparações entre escoamentos reativos e inertes também são realizadas na experiência. 


\section{Metodologia}

Neste capítulo serão apresentadas as equações governantes do problema estudado, as condições de contorno do que descrevem o problema e o método numérico do pacote CFX 5.7.1.

\section{1}

\section{Equações Governantes}

As equações que governam o sistema são as equações de Navier-Stokes em sua forma conservativa. Assim as equações de conservação de massa, momento e energia são descritas por

$$
\begin{gathered}
\frac{\partial \rho}{\partial t}+\nabla \bullet(\rho \mathbf{U})=0 \\
\frac{\partial \rho \mathbf{U}}{\partial t}+\nabla \bullet(\rho \mathbf{U} \otimes \mathbf{U})=\nabla \bullet\left(-p I+\mu\left(\nabla \mathbf{U}+\left(\nabla \mathbf{U}^{T}\right)\right)\right. \\
\frac{\rho H}{\partial t}-\frac{\partial p}{\partial t}+\nabla \bullet\left(\rho \mathbf{U} h_{t o t}\right)=\nabla \bullet(\lambda \nabla T)+S_{E}
\end{gathered}
$$

sendo $\rho, \mathbf{U}$ T e p definidos como densidade, velocidde, temperatura e pressão do escoamento, $H$, entalpia específica total que é definida por $H=$ $h+1 / 2 u^{2}$.

A equação de transporte de massa de cada espécie química é dada por

$$
\frac{\partial\left(\rho Y_{I}\right)}{\partial t}+\frac{\partial\left(\rho u_{j} Y_{I}\right)}{\partial x_{j}}=\frac{\partial}{\partial x_{j}}\left(\Gamma_{I_{e f f}} \frac{\partial Y_{I}}{\partial x_{j}}\right)+S_{I}
$$

onde $S_{I}$ é um termo fonte, a taxa de reação química da espécie $I$,

A taxa de reação química é descrita em termos dos $K$ elementos da reação

$$
\sum_{I=A, B, C, \ldots}^{N_{c}} \mathrm{v}_{k I}^{\prime} I \rightleftharpoons \Sigma_{I=A, B, C, \ldots}^{N_{c}} \mathrm{v}_{k I}^{\prime \prime} I
$$

onde $v_{k I}$ é o coeficiente estequiométrico da reação $k$ do elemento $I$. 
A taxa de produção/consumo, $S_{I}$, é calculada a partir da soma da taxa de reação de todos os elementos,

$$
S_{I}=W_{I} \Sigma_{I=A, B, C, \ldots}^{N_{c}}\left(v_{k I}^{\prime \prime} v_{k I}^{\prime}\right) R_{k}
$$

onde $R_{k}$ é a taxa do processo de reação $k$ apresentada a seguir.

\section{2}

\section{Modelos de Combustão}

O modelo de combustão utilizado foi uma combinação dos modelos $E d d y$ Dissipation e Finite Rate Chemistry. A taxa de reação dada pela combinação dos dois modelos é taxa a mínima entre a taxa do modelo Eddy Dissipation e o Finite Rate Chemistry.

O modelo Eddy Dissipation tem como fundamento que a reação química ocorre mais rapidamente do que o processo de transporte do escoamento. Assim, quando os reagentes se misturam a nível molecular, instantâneamente os produtos são formados. Este modelo assume que a taxa de reação está diretamente relacionada com o tempo em que os reagentes levam para se misturarem a nível molecular. Em escoamentos turbulentos essa taxa é dominada pelas propriedades turbulentas, portanto, a taxa é proporcional a um tempo de mistura definida pela energia cinética turbulenta, $k$, e a sua taxa de dissipação $\varepsilon$.

Este conceito de controle da reação é aplicado em diversos problemas de combustão a nível industrial onde a taxa de reação química é mais rápida do que a taxa de mistura das espécies.

A taxa de reação química, $k$ é determinada a partir do menor valor entre os reagentes limitantes (eq 2-7)

$$
R_{k}=A \frac{\varepsilon}{k} \min \left(\frac{[I]}{v_{k I}^{\prime}}\right)
$$

e os produtos limitantes (eq, 2-8,

$$
R_{k}=A B \frac{\varepsilon}{k} \min \left(\frac{\Sigma_{P}[I] W_{I}}{\Sigma_{P} \vee_{k I}^{\prime \prime} W_{I}}\right)
$$

onde $[I]$ é a concentração molar do componente $I$ incluindo apenas os componentes dos reagentes.

No modelo Finite Rate Chemistry assume-se que a taxa de reação pode ser reversível somente se existir uma reação de retorno. Assim a taxa de reação $R_{k}$ é dada por, 


$$
R_{k}=\left(F_{k} \Pi_{I=A, B, \ldots}^{N_{c}}[I] r_{k I}^{\prime}-B_{k} \Pi_{I=A, B, \ldots}^{N_{c}}[I] r_{k I}^{\prime \prime}\right)
$$

onde $[I]$ é a concentração molar do componente $I$ e $F_{k}$ e $B_{k}$ são as taxas de avanço e retorno da reação $k$.

\section{3}

\section{Condições de Contorno}

Em cada um dos problemas estudados, foram supostos escoamento bidimensional e a existência de uma linha de simetria.

As condições de contorno para o caso do canal são apresentadas na Fig 2.1 enquanto que a Fig.2.2. Assim temos

1. entrada: vazão, temperatura, composição química da mistura, energia cinética e escala de comprimento da turbulência especificados.

2. parede sem deslizamento: $u=v=0$, parede adiabática e não catalítica, lei da parede.

3. simetria: $\frac{d \phi}{d x}=0$ sendo $\phi=\left(u, v, p, T, Y_{i}, k, \varepsilon\right)$

4. saída: vazão especificada.

5. farfield: condição de escoamento não perturbado.

6. periodicidade

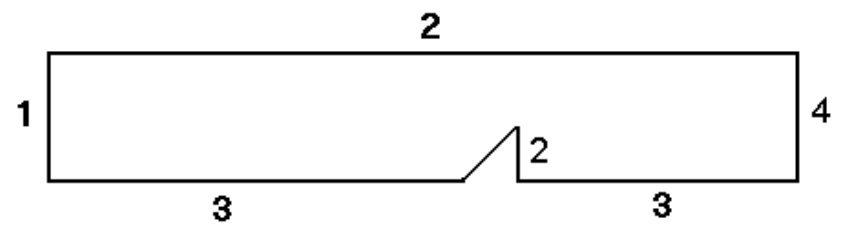

Figura 2.1: Condições de contorno para o caso do canal com obstáculo.

Note-se que o programa computacional utilizado realiza somente cálculos tri-dimensionais. Assim, os domínios de cálculo utilizados possuem dois volumes computacionais na direção normal a $x$ e $y$. Nestas direções condições de contorno de periodicidade são utilizadas no caso do queimador, enquanto que simetria plana é imposta no caso do canal. 
5

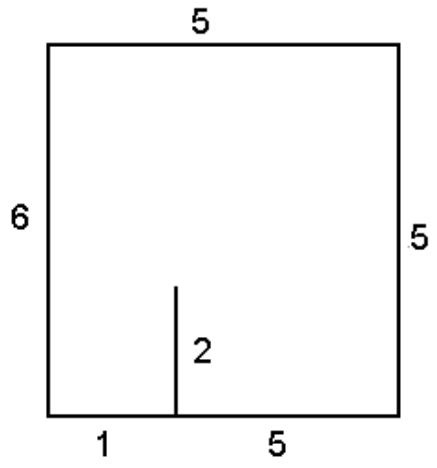

Figura 2.2: Condições de contorno para o caso do queimador. 


\section{Resultados e Discussões}

3.1

Condições de Cálculo

As condições de cálculo para os casos i1 e i3 e r1 e r3 são apresentados na tabela 1.

Tabela 1 - Valores de vazão e velocidade axial dos casos simulados.

\begin{tabular}{|c|c|c|}
\hline Caso & $\dot{m}[1 / \mathrm{s}]$ & $U_{\text {axis }}[m / s]$ \\
\hline i1 & 12 & 2.54 \\
\hline i3 & 36 & 7.51 \\
\hline r1 & 12 & 6.26 \\
\hline r3 & 36 & 17.38 \\
\hline
\end{tabular}

Em cada um dos casosa temperatura e a pressão na entrada são $300 K$ para o caso inerte e $1280 \mathrm{~K}$ para o caso reativo e $1 E+5 \mathrm{~Pa}$.

Nos casos reativos $r 1$ e $r 3$, a mistura de propano e de ar tem uma riqueza de e o mecanismo de reação química utilizado é o WGS.

A Fig 3.1 apresenta as dimensões do domínio de cálculo utilizado para representar o canal. O escoamento foi considerado bi-dimensional. O obstáculo apresenta 9,6 $\mathrm{mm}$ de altura e uma base de $8,3 \mathrm{~mm}$. O comprimento utilizado no domímio de cálculo foi o próprio comprimento do canal, $2300 \mathrm{~mm}$ e a altura utilizada foi a metade da altura total do canal, 14,4 $\mathrm{mm}$

\section{2}

\section{Malhas Computacionais}

O software utilizado para a geração de malha foi o ICEMCFD. Neste software a geração de malha hexaédrica é feita através a construção de blocos e projeção das arestas destes blocos na geometria. A escolha de malhas hexaédricas é motivada pela simplicidade geométrica dos problemas estudados e pelo melhor controle do refinamento junto a paredes que este tipo de 


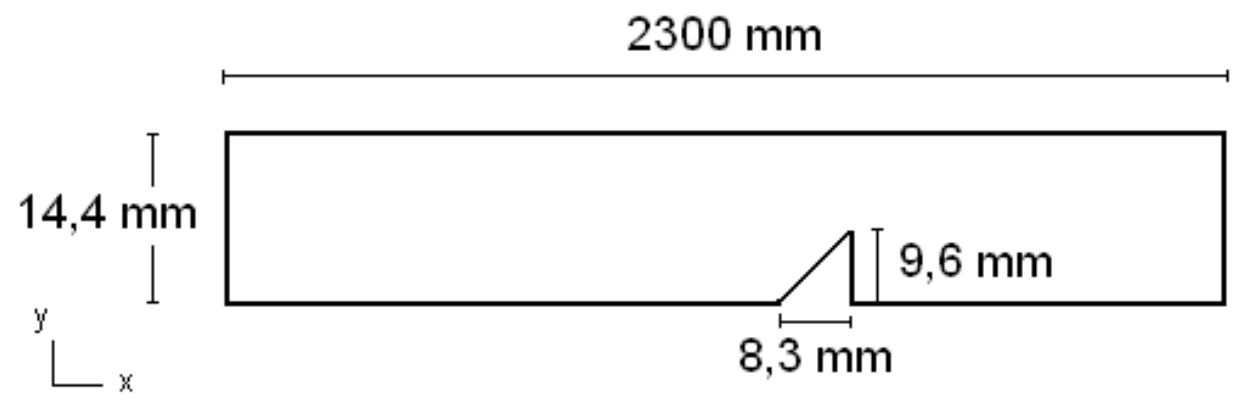

Figura 3.1: ESquema do domínio de cálculo e suas dimensãoes.

malha possibilita. Além disto, espera-se obter um menor tempo computacional, pois a utilização deste tipo de malha facilita a convergência. Cabe ressaltar que a geração de malhas tetraédricas ocorre de forma mais automática, o usuário fornecendo apenas os tamanhos dos elementos em cada região da geometria. É geralmente aplicada em casos com geometrias de grande complexidade.

A malha gerada para o caso do queimador possui 9062 nós e 5848 elementos. A malha próxima as paredes do queimador estão mais refinadas para melhor restituir o comportamento da camada limite.

O mesmo procedimento foi adotado para a geração da malha para o segundo caso estudado. A Fig 3.2 apresenta a malha gerada. Esta malha possui 40950 nós e 19920 elementos. Embora a região de interesse situe-se apenas a jusante do obstáculo, a malha cobre a totalidade do comprimento da instalação experimental. Isto foi feito de modo a garantir um perfil de velocidades perfeitamente desenvolvido a montante do obstáculo e uma fronteira de saída situada suficientemente distante da região de interesse.

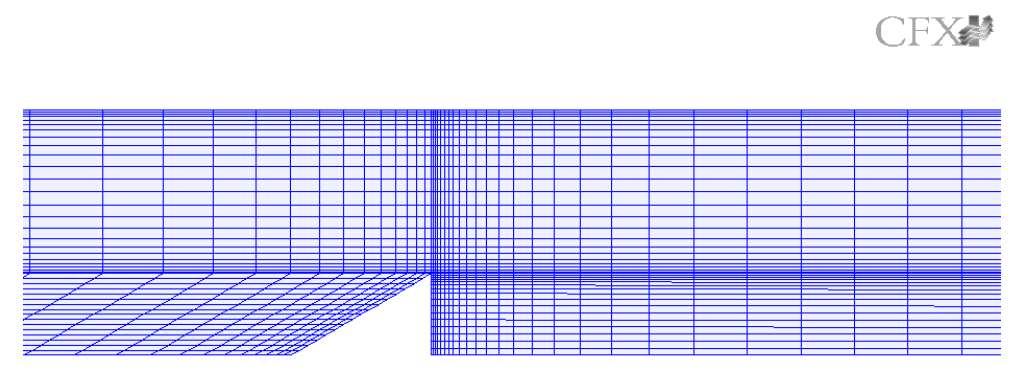

Figura 3.2: Malha hexaédrica próxima ao obstáculo.

Note-se que em nenhum dos casos estudados foi realizado um estudo de sensibilidade do resultado obtido à escolha da malha computacional. 


\section{3}

\section{Estrutura do Escoamento Inerte}

A montante do obstáculo o escoamento está completamente desenvolvido, ou seja, as condições iniciais não interferem em seu comportamento, sendo o gradiente de pressão constante e a velocidade transversal independente da posição longitudinal $x$. Estas são características de um escoamente de Poiseuille, ou seja, escoamento de canal.

A Fig 3.3 apresenta os vetores de velocidade para o caso inerte. Observa-se que o escoamento é desviado pelo obstáculo. Nessa posição há um aumento da velocidade.

A jusante do obstáculo ocorre a formação de uma zona de recirculação de comprimento médio $X_{r}$.

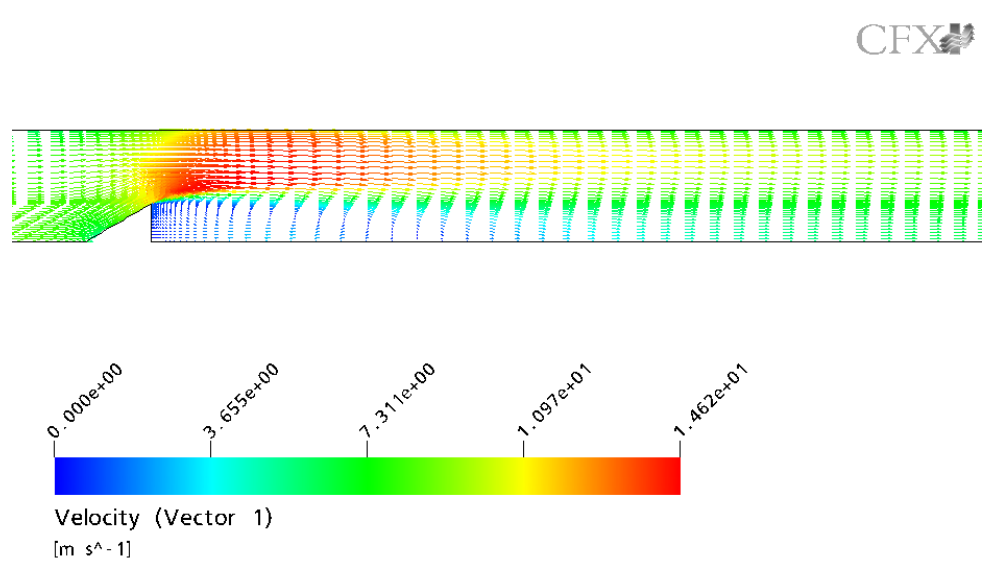

Figura 3.3: Vetores velocidades para o caso inerte i1.

A Fig 3.4 apresenta o campo de enegia cinética turbulenta para o caso $i 1$. Observando-se o campo de energia cinética turbulenta, nota-se a presença de uma região de alta energia cinética turbulenta. Essa região apresenta altas tensões cisalhantes. Esse campo não sofre modificações para o caso $i 3$ como mostra a Fig 3.5

\section{4}

\section{Estrutura do Escoamento Reativo}

Como mostrado na Fig. 3.6, a estrutura dos campos de velocidade do escoamento reativo seguem o mesmo padrão dos casos inertes. Assim temos o campo de vetores velocidade para o caso reativo, onde o escoamento é desviado pelo obstáculo. A partir dai há um aumento da velocidade do escoamento. Notase a presença de uma zona de recirculação. 

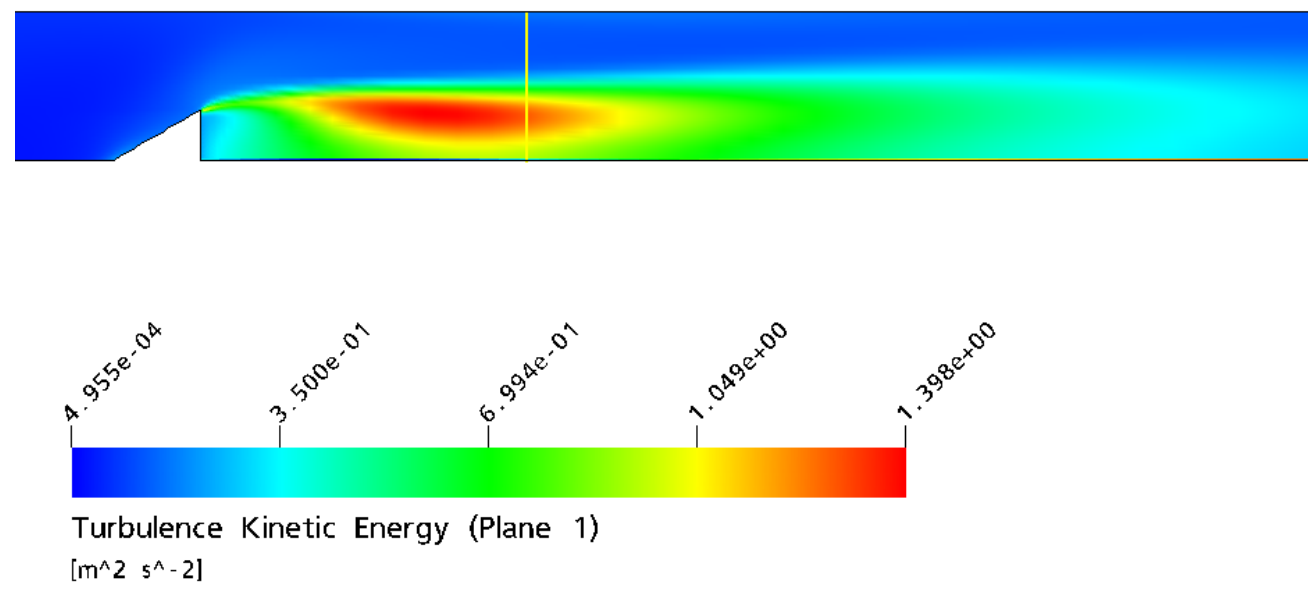

Figura 3.4: Energia cinética da turbulência para o caso inerte i1.

A Fig 3.7 apresenta a distribuição de temperatura ao longo do canal. Logo após o obstáculo aparece a chama ancorada. Porém, nota-se que não ocorre queima dos gases frescos mais a jusante do obstáculo próximo a parede. Isto pode ser uma indicação de que o modelo de combustão é impróprio para esta situação.

Alguns resultados foram obtidos utilizando os modelos de combustão Eddy Dissipation e Finite Rate Chemistry separados. A Fig 3.8 mostra a distribuição de temperatura utilizando o modelo Eddy Dissipation. Nota-se que não é possível estabilizar a combustão a jusante do obstáculo, esta ocorre imediatamente após a entrada da mistura no canal. Observando os campos da frequência turbulenta na entrada do canal e próximo ao obstáculo, nota-se que não seria possível estabilizar a combustão com os valores de frequência turbulenta, $\omega=\varepsilon / k$ presentes no escoamento.

Ao utilizar o modelo de combustão Finite Rate Chemistry, a propagação da da chama ocorre como se a chama fosse uma chama laminar. Isto pode ser observado na Fig. 3.4. Este resultado também não representa os experimentos. 

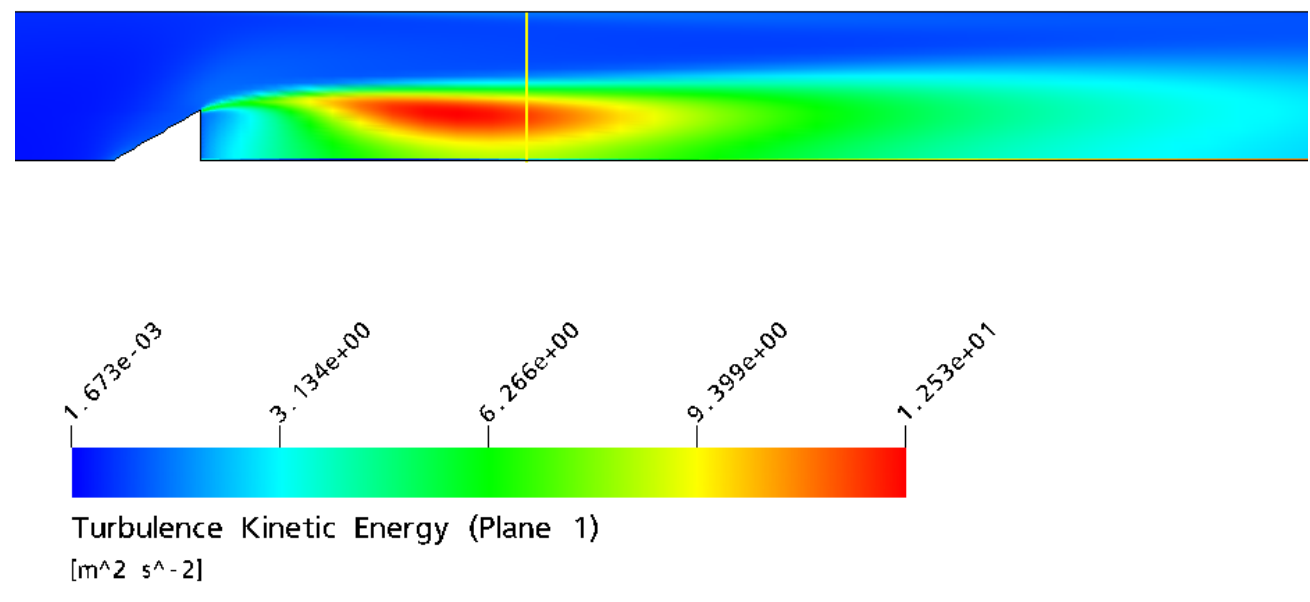

Figura 3.5: Energia cinética da turbulência para o caso inerte i3.

\section{5}

\section{Comparação com Resultado Experimental}

A Fig 3.10 apresenta a evolução longitudinal ao longo do eixo de simetria obtida para os casos inertes simulados. A Fig 3.11 mostra os respectivos dados experimentais 2]. Comparando-se os resultados experimental e numérico, observase que o comprimento da zona de recirculação encontrado é bem próximo do valor experimental. Além disto, os valores da velocidade axial também encontram-se dentro da faixa esperada. Uma comparação entre os diferentes esquemas de discretização espacial utilizados, Upwind e High Res (segunda oredem), é mostrada. A diferença observada entre os esquemas é pequena.

A evolução da velocidade longitudinal ao longo do eixo de simetria obtidas para o caso reativo é semelhante à do caso inerte. Entretanto uma diferença maior entre os diferentes esquemas de interpolação utilizados foi obtida em particular na região de velocidades negativas. Estes resultados são apresentados nas Fig. 3.12 e Fig. 3.13

A tabela 2 apresenta uma comparação entre o cálculo e o experimento para os valores do comprimento da zona de recirculação, os valores teóricos foram 

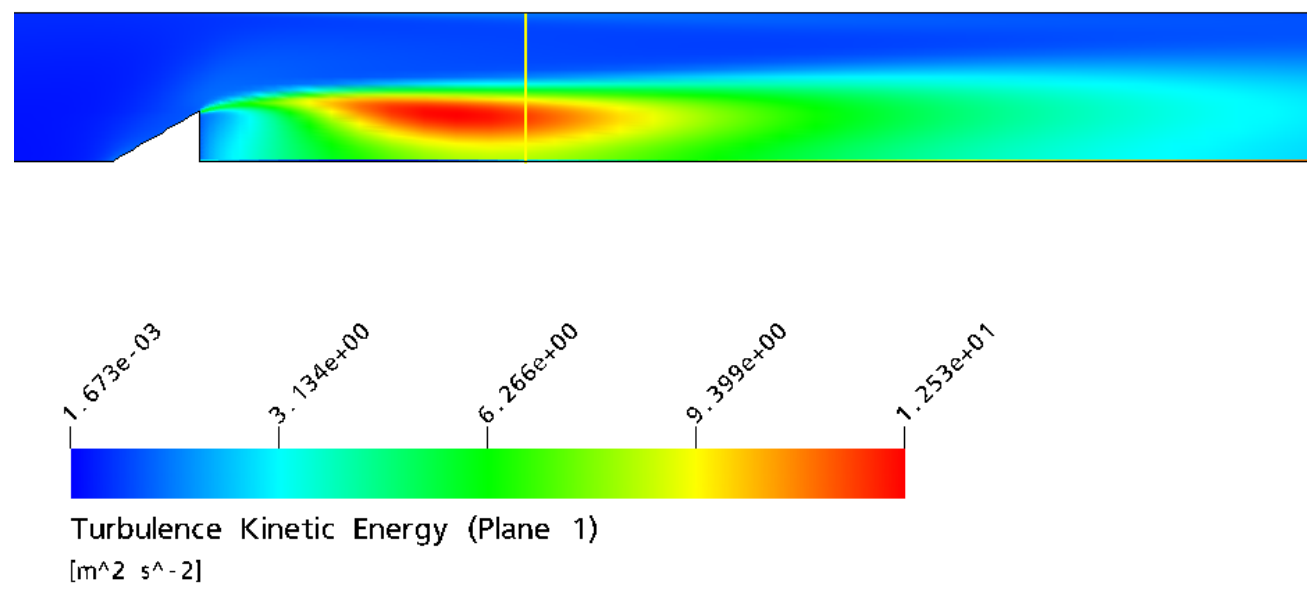

Figura 3.6: Vetores velocidade para o caso reativo r1.

calculados a partir da média dos valores obtidos para diferentes esquemas de interpolação.

Tabela 2 - Comparação entre os valores de $X_{r}$ experimentais e numéricos.

\begin{tabular}{|c|c|c|c|}
\hline Caso & Experimental & Numérico & Erro \% \\
\hline i1 & 0.19 & 0.174 & 8.40 \\
\hline i3 & 0.15 & 0.163 & 8.70 \\
\hline r1 & 0.23 & 0.215 & 6.50 \\
\hline r3 & 0.40 & 0.387 & 3.25 \\
\hline
\end{tabular}

Observa-se um excelente acordo entre resultados numéricos e experimentais.

A evolução transversal da velocidade longitudinal se comporta de forma semelhante para os casos inertes e reativos como pode ser observado nas Fig 3.14 e Fig. 3.15. A diferença obtida entre os esquemas de interpolação não foi grande. Um bom acordo pode ser observado entre resultados experimentais e de cálculo. 

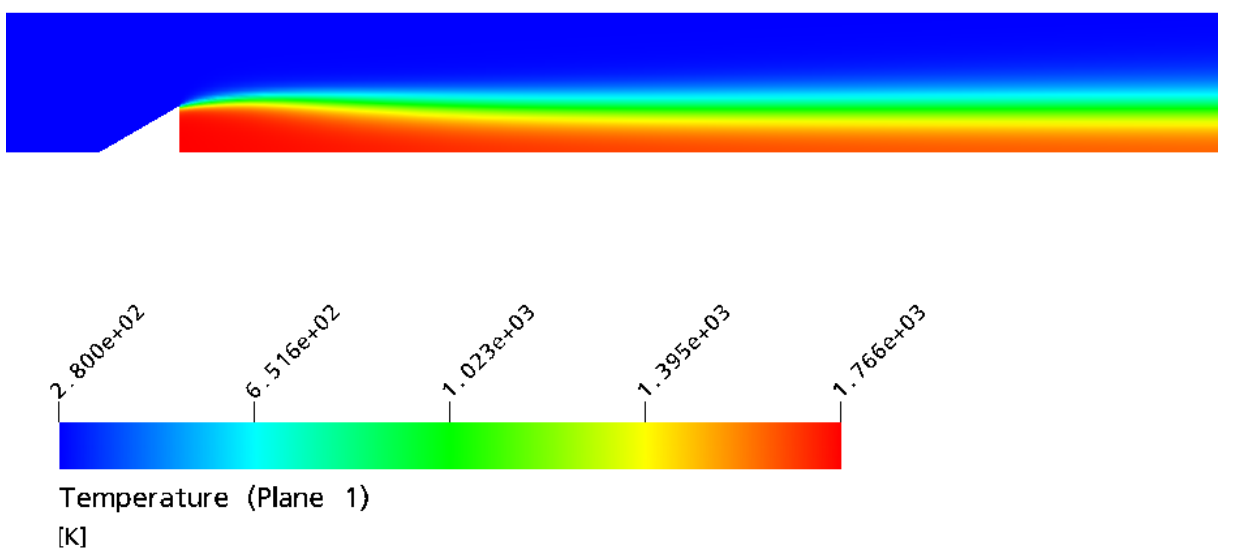

Figura 3.7: Distribuição de temperatura ao longo do canal, caso r1.

Obteve-se resultados para a velocidade transversal adimensionalisada pela velocidade axial do escoamento, que são mostradas nas Fig 3.16 e Fig3.17 para os casos inertes e Fig 3.18 e Fig 3.5 para os casos reativos . Esses resultados apresentam uma diferença nos valores da velocidade tanto para o caso inerte quanto para o caso reativo.

\section{6}

\section{Gráficos de Convergência dos Casos Simulados}

Durante as simulações utilizou-se dois sistemas de discretização espacial diferentes, o Upwind e o High Resolution. Por não apresentarem grandes diferenças no tempo de convergência, serão apresentados os gráficos apenas da discretização espacial Upwind.

A Fig 3.21 apresenta o gráfico de convergência do caso inerte $i 1$, que convergiu em aproximadamente 90 iterações. A convergência das quantidades turbulentas também são apresentadas.

$\mathrm{O}$ caso inerte $i 3$ convergiu em aproximadamente 95 iterações. A Fig 3.21 apresenta o gráfico de convergência deste caso, juntamente com a convergência das quantidades turbulentas. 


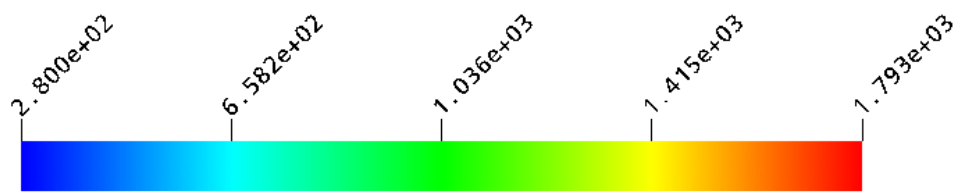

Temperature (Plane 1)

$[\mathrm{K}]$

Figura 3.8: Distribuição de temperatura na entrada do canal para o modelo de combustão Eddy Dissipation.

Como pode-se observar, os casos inertes convergiram em aproximadamente 100 iterações, com um tempo médio de duas horas em um Pentium IV $2.2 \mathrm{GHz} /$ Linux.

Note-se que para os casos reativos o número de iterações foi maior e a convergência oscilou bastante. Uma explicação para este problema seria que a hipótese de regime permanente para o problema não é mais adequada. A Fig. 3.22 apresenta o gráfico de convergência para o caso reativo $r 1$ e a Fig 3.23 apresenta o gráfico de convergência para o caso reativo $r 3$ 

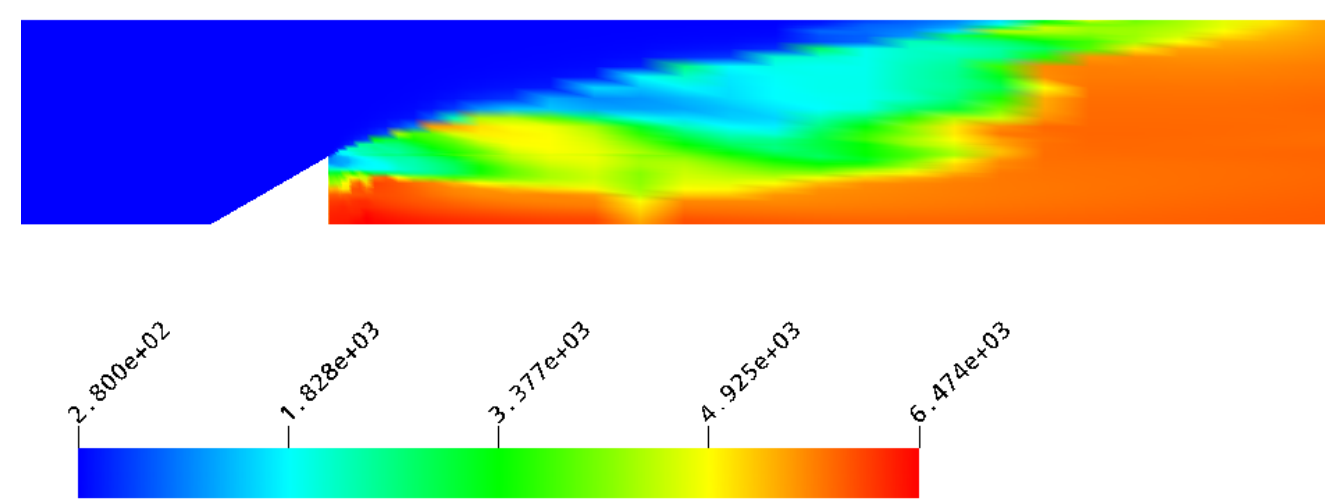

Temperature (Plane 1)

[K]

Figura 3.9: Distribuição de temperatura no canal para o modelo de combustão Finite Rate Chemistry. 


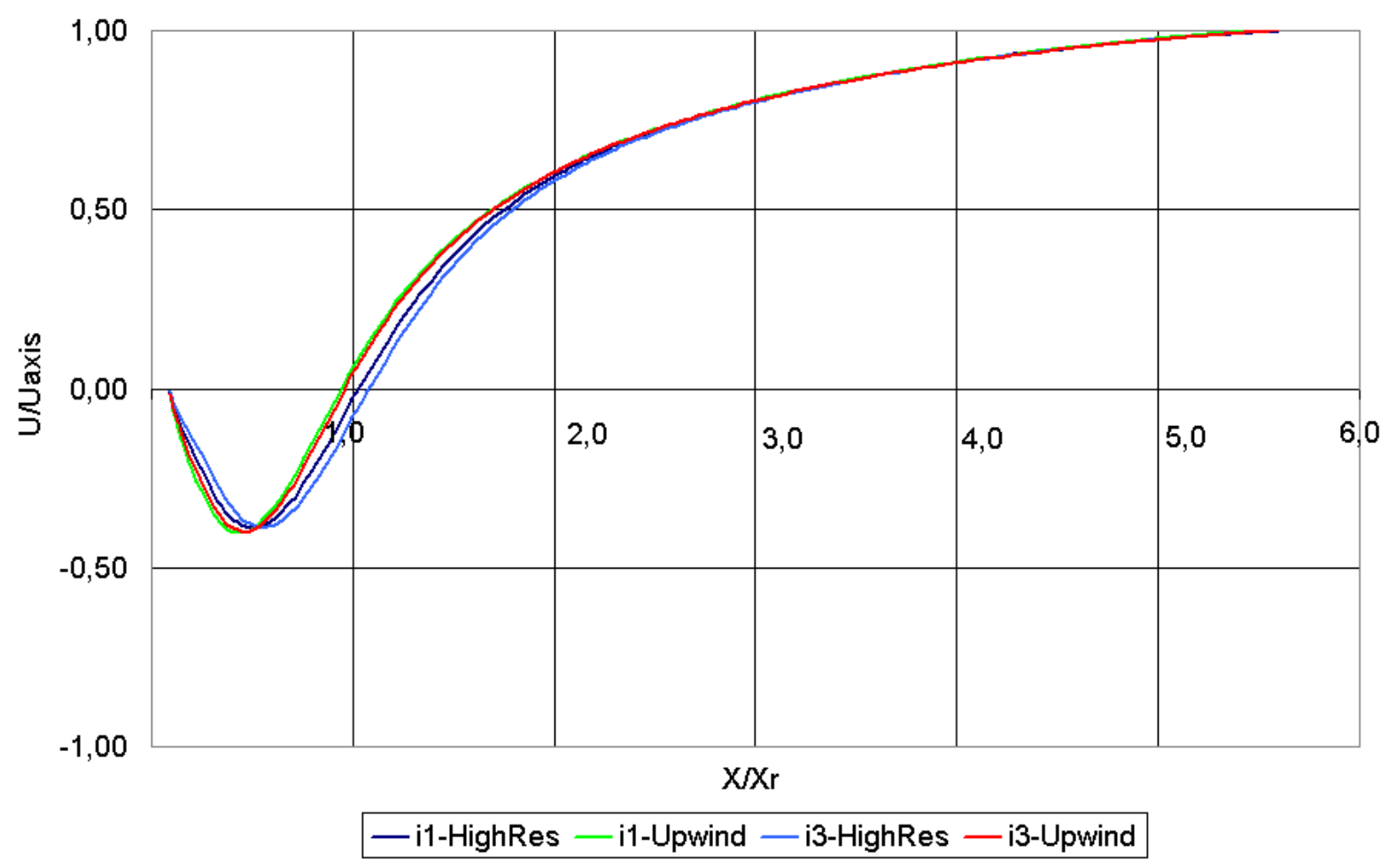

Figura 3.10: Evolução longitudinal da velocidade para os casos inertes.

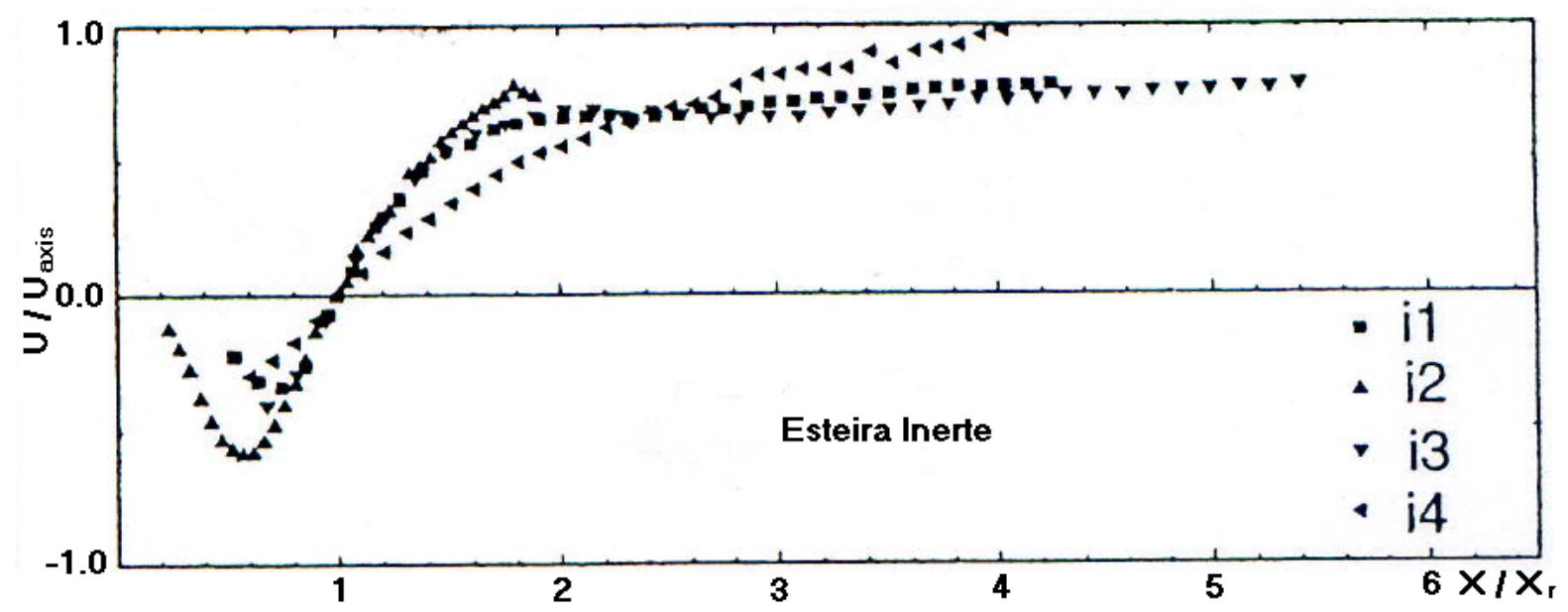

Figura 3.11: Evolução longitudinal da velocidade para os casos inertes experimental. 


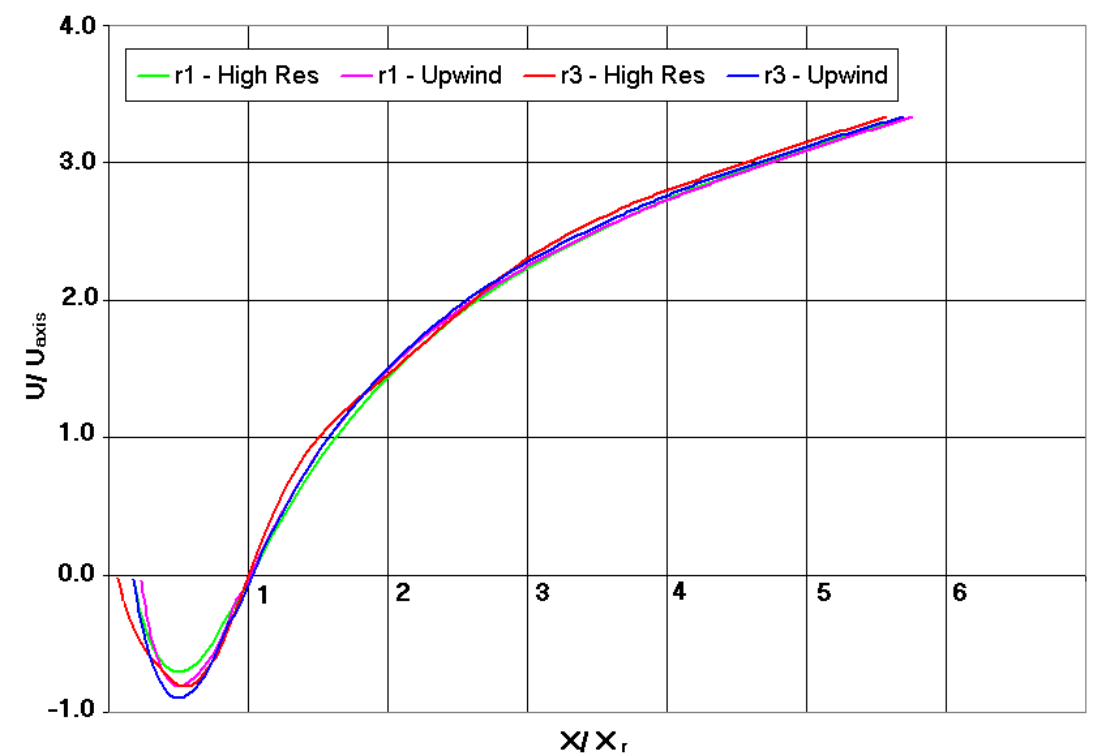

Figura 3.12: Evolução longitudinal da velocidade para o caso reativo.

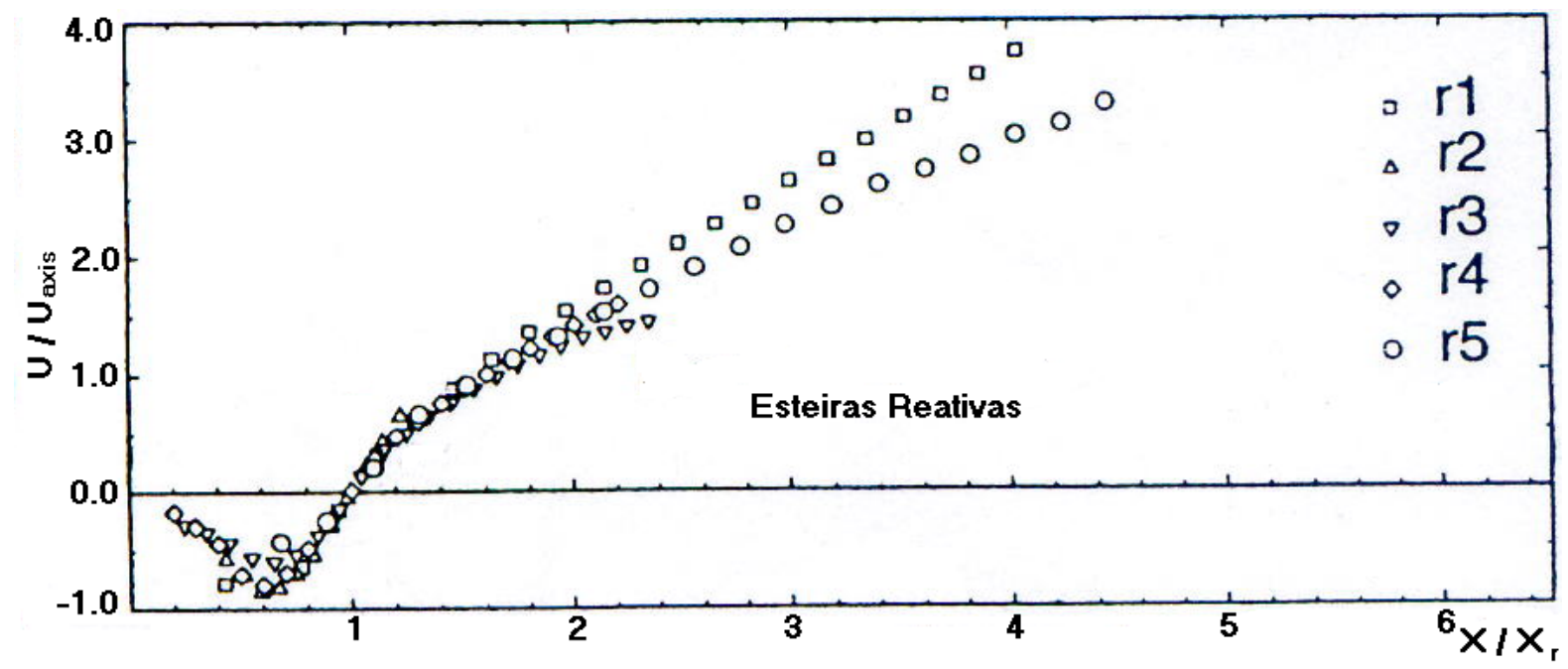

Figura 3.13: Evolução longitudinal da velocidade para o caso reativo experimental. 


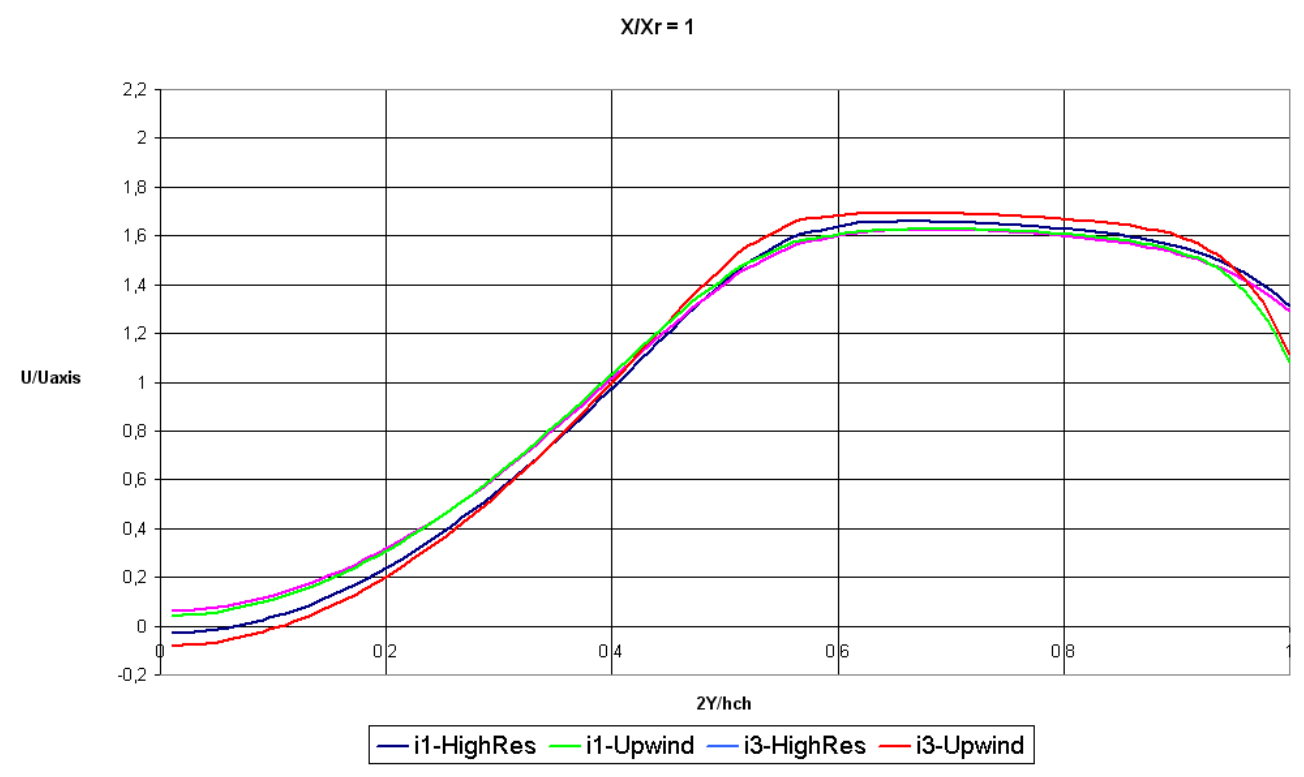

Figura 3.14: Gráfico com a evolução longitudinal para os casos inertes.

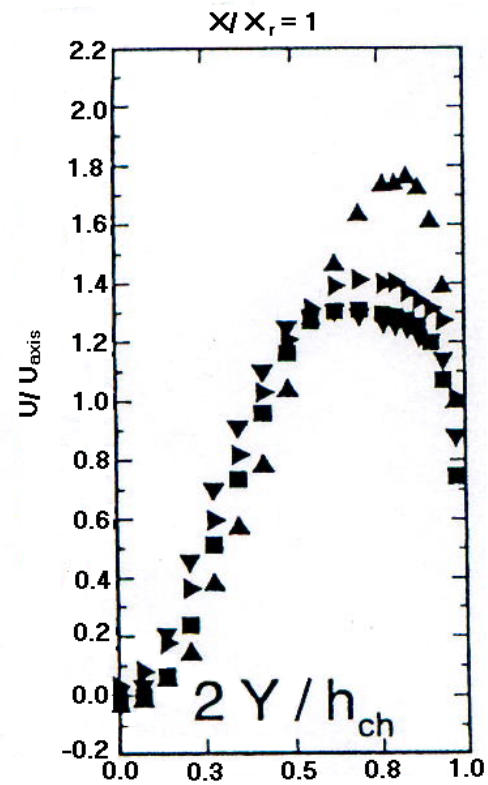

Figura 3.15: Gráfico com a evolução longitudinal para os casos inertes experimental. 


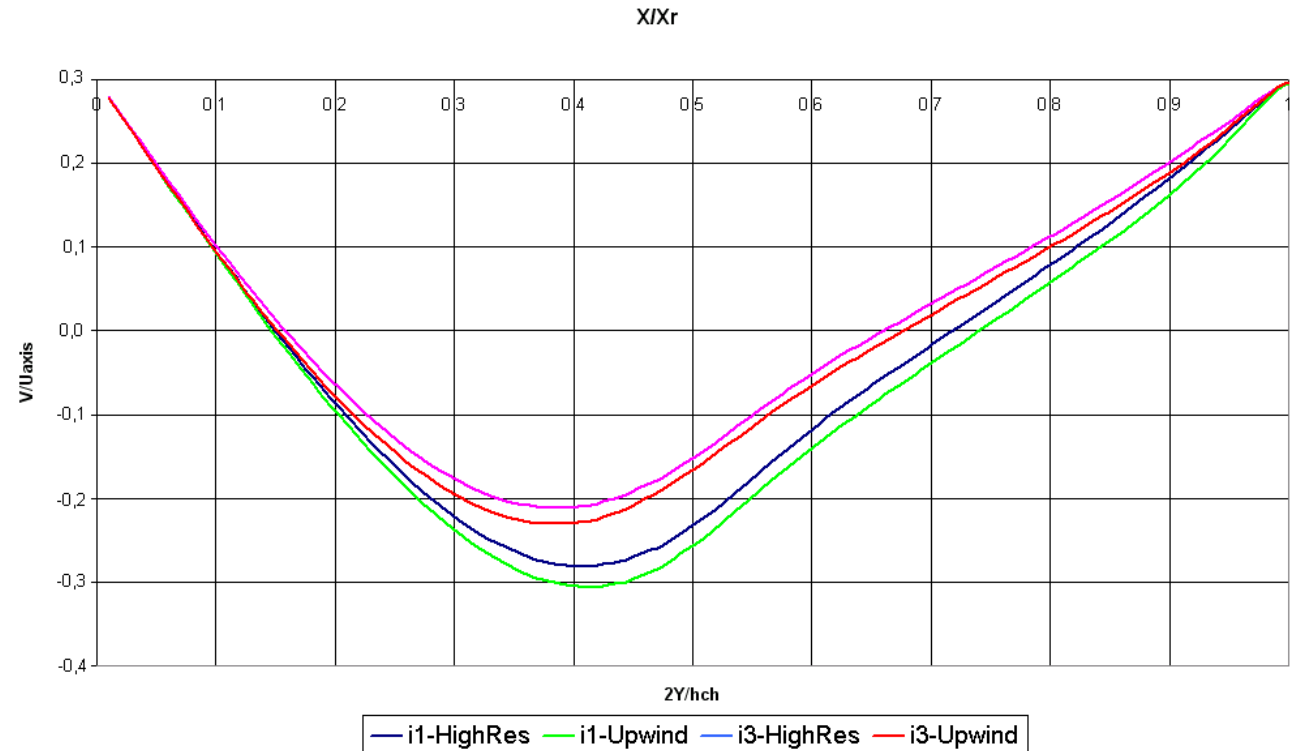

Figura 3.16: Evolução da velocidade transversal $v$ inerte.

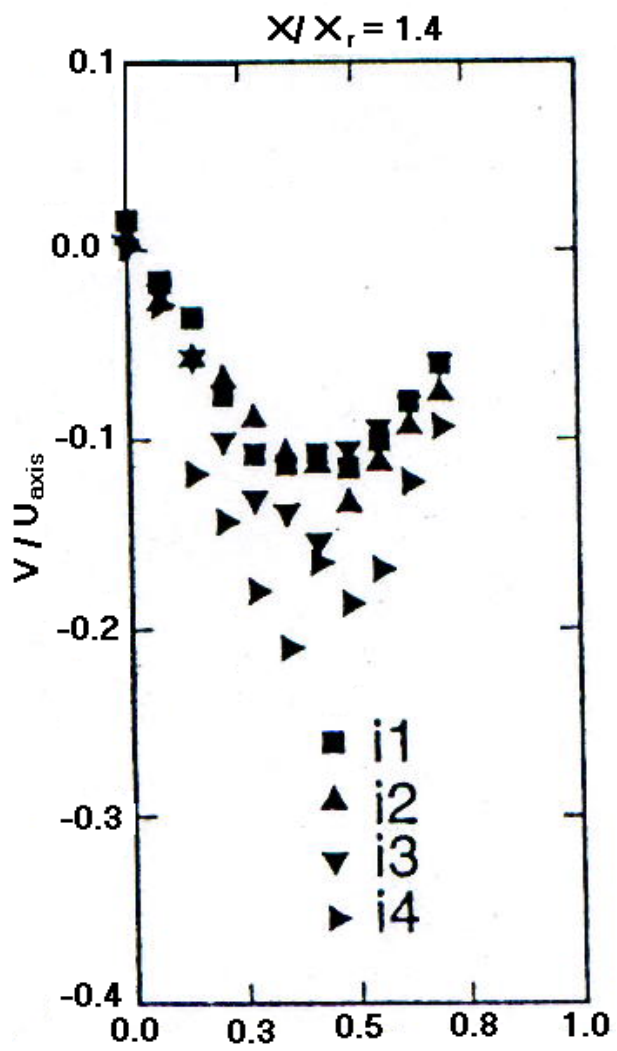

Figura 3.17: Evolução da velocidade transversal $v$ inerte experimental. 


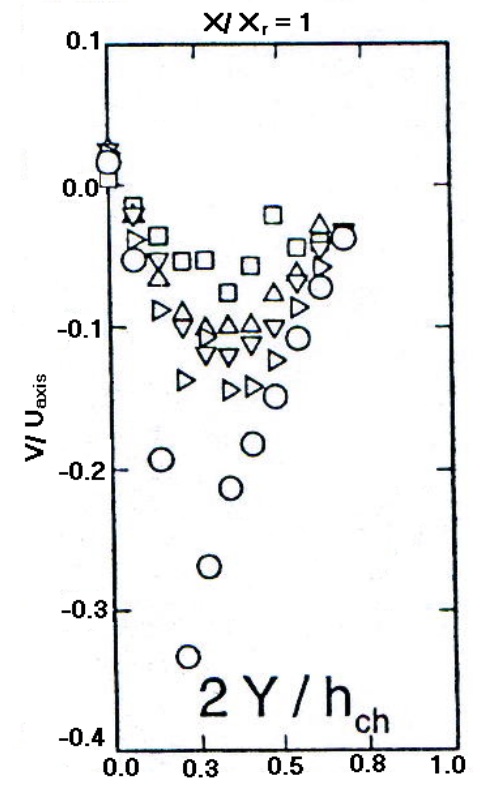

Figura 3.18: Evolução da velocidade transversal $v$ reativo.

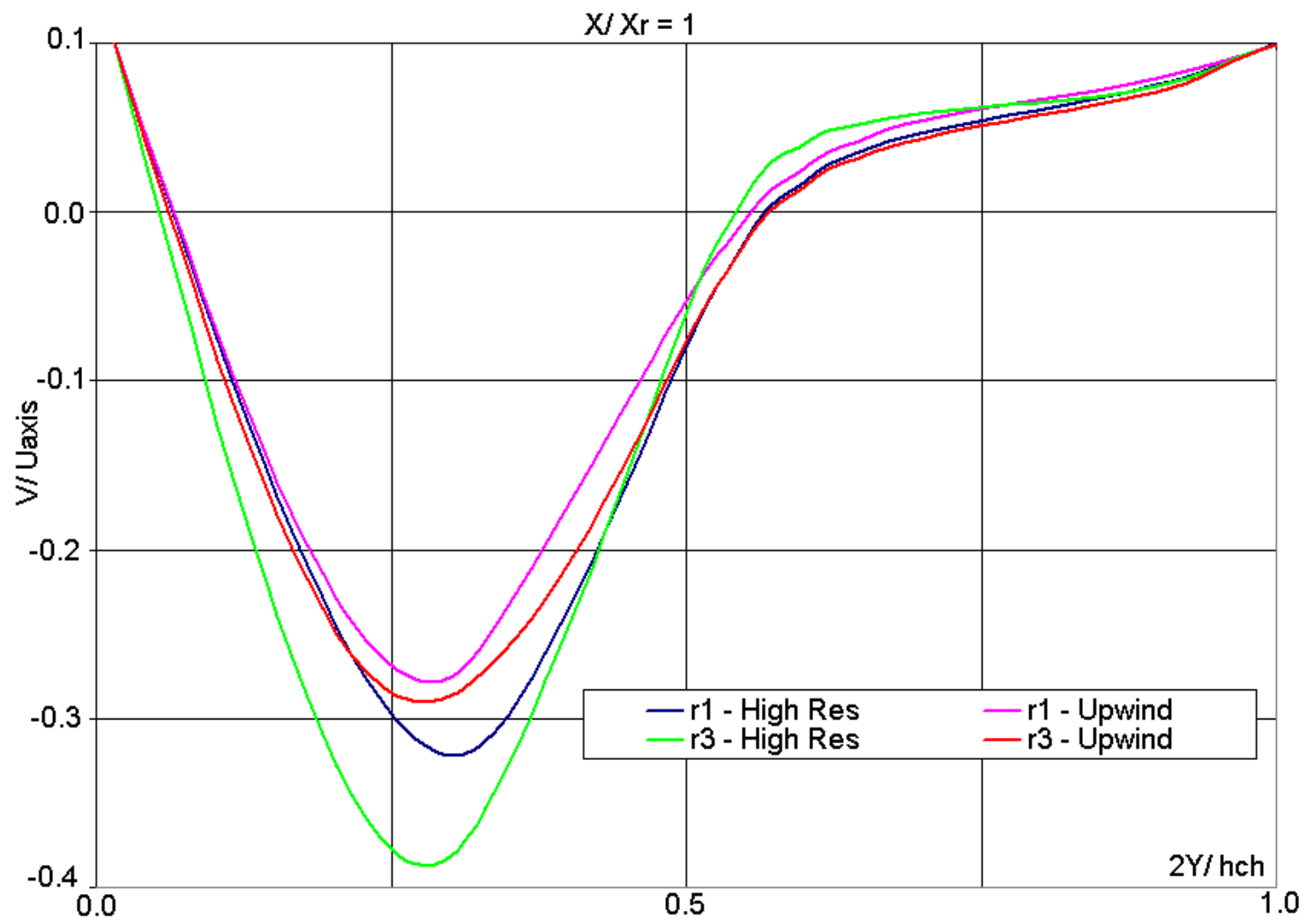

Figura 3.19: Evolução da velocidade transversal $v$ reativo experimental. 

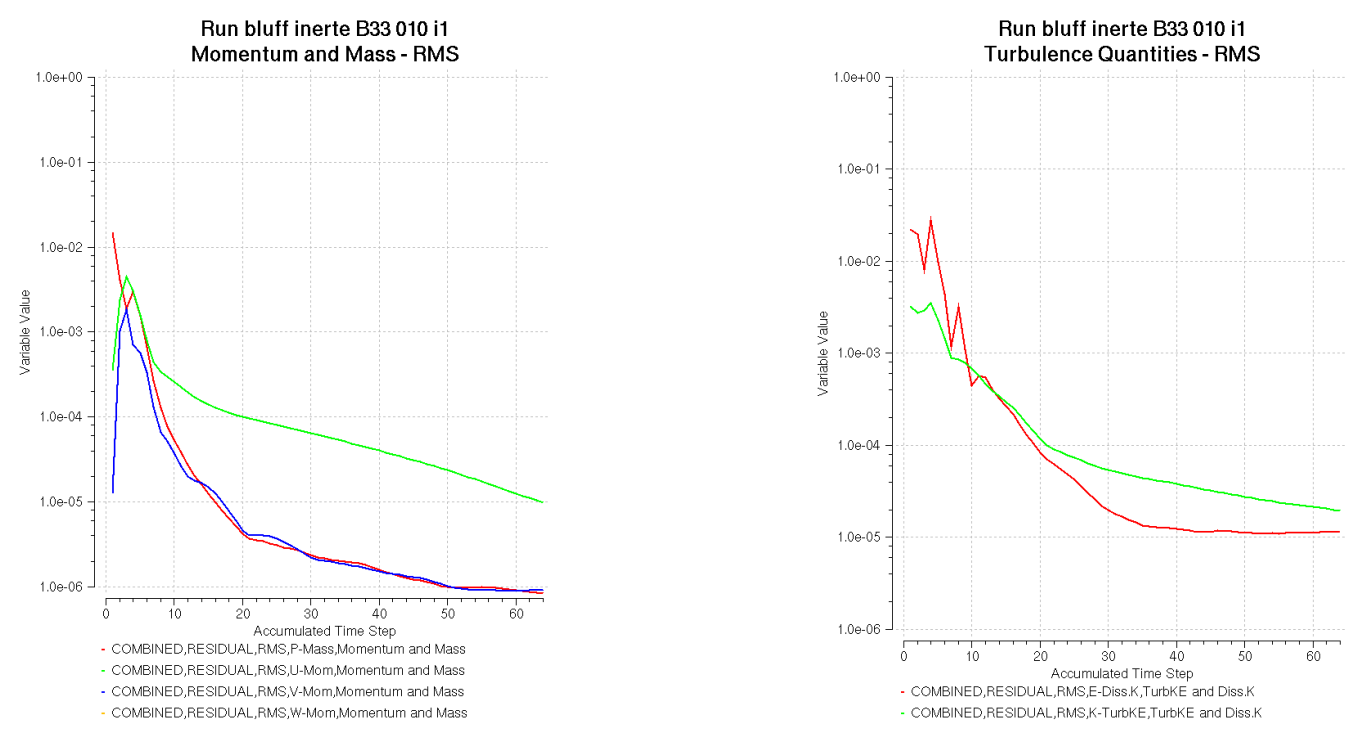

Figura 3.20: Gráfico de convergência do caso i1.
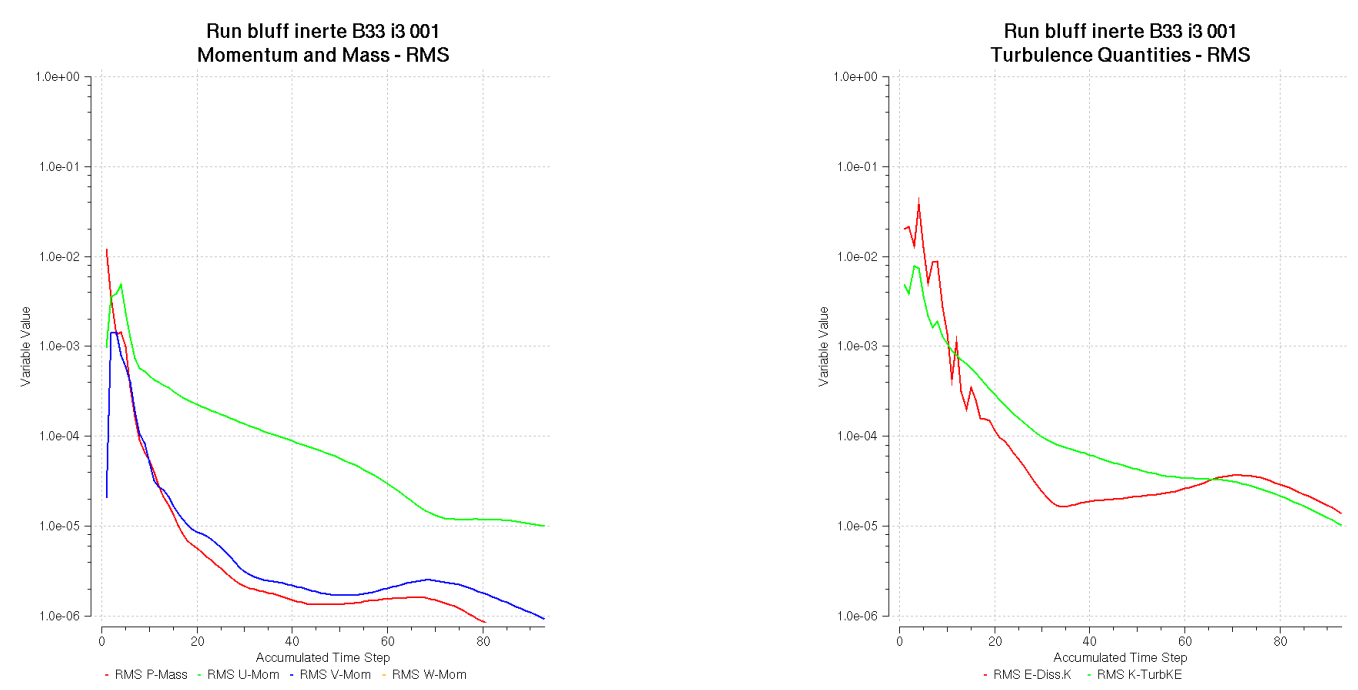

Figura 3.21: Gráfico de convergência do caso i3.
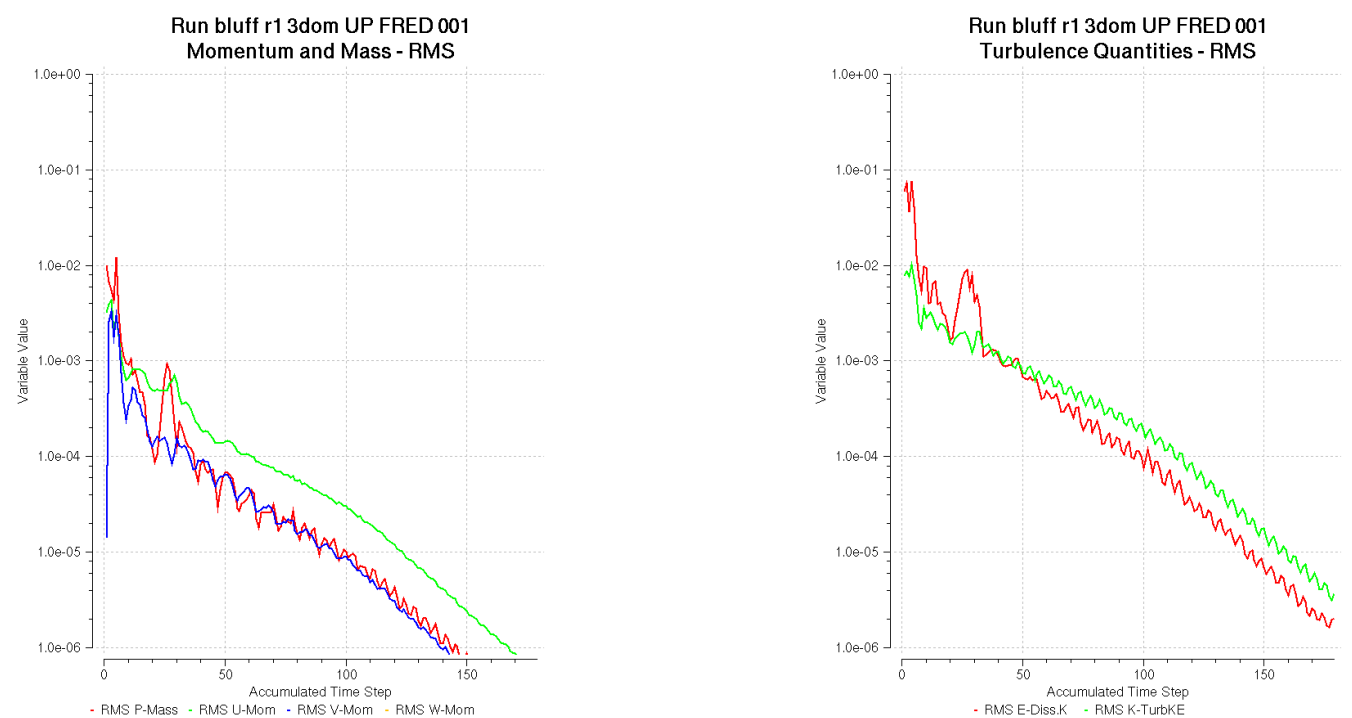

Figura 3.22: Gráfico de convergência do caso r1. 

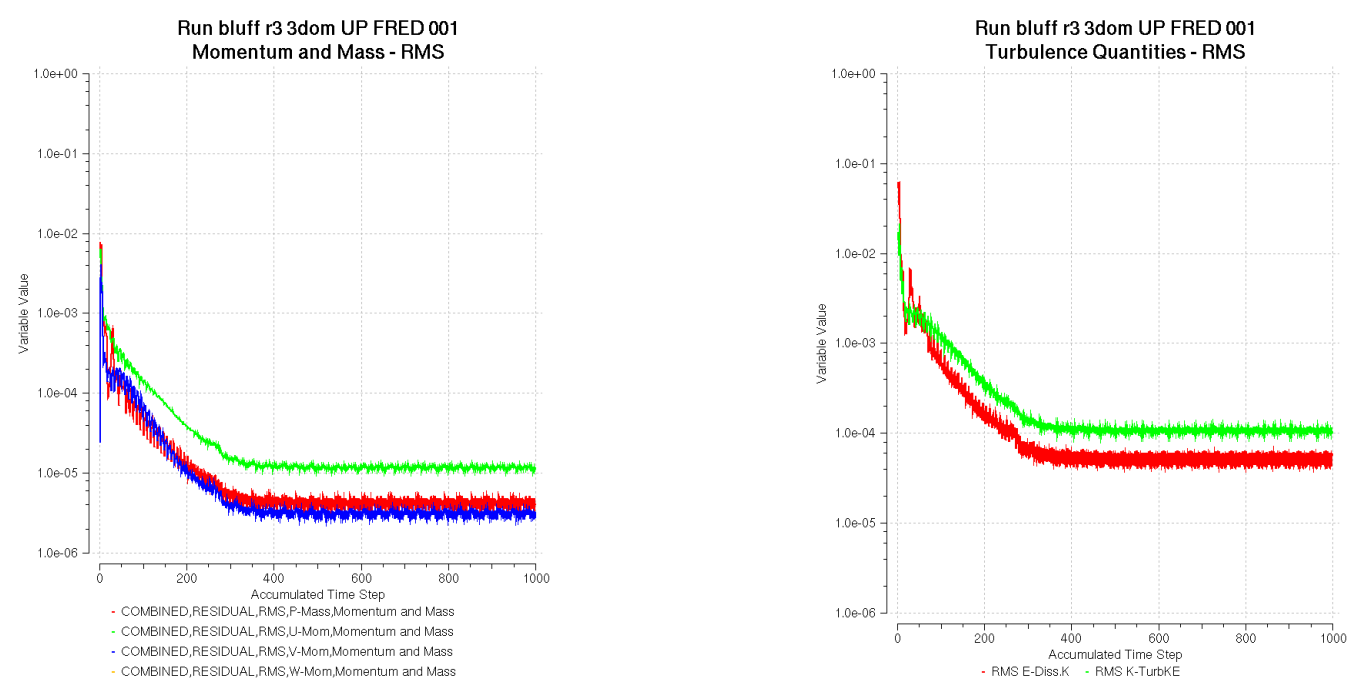

Figura 3.23: Gráfico de convergência do caso r3. 


\section{4 \\ Conclusão e Perspectivas}

Este trabalho apresentou uma comparação entre os resultados numéricos obtidos com os modelos de combustão existentes no CFX-5.7.1 e resultados experimentais no caso da combustão turbulenta de uma mistura de propana e de ar a jusante de um obstáculo. Também foi investigada a influência do esquema de discretização espacial sobre os resultados dos cálculo.

Os resultados de cálculo mostraram, para o caso inerte, uma boa concordância com os resultados experimentais, para todos os esquemas de discretização avaliados.

No caso reativo as simulações prevêem uma velocidade transversal maior que a medida. A utilização de um modelo não adequado para este problema poderia justificar esta diferença de velocidade transversal encontrada.

Uma maneira de melhorar o acordo entre cálculo e experimentais seria de realizar simulações com modelos de turbulência mais sofisticados, como o LES por exemplo. Além disso, seria necessário a realização de testes com outros modelos de combustão que se encontram no CFX-RIF, que não está disponível no momento. 


\section{Bibliografia}

[1] BÉDAT, B.AND CHENG, R.. Experimental study of premixed flames in intense isotropic turbulence. Combustion and Flame, 100:485-494, 1995.

[2] SANQUER, S.; BRUEL, P.AND DESHAIES, B.. Some specific characteristics of turbulence in the reactive wakes of bluff bodies. 32nd Joint Propulsion Conference, 36:994-1001, 1998.

[3] MARTINS, C.. Investigação da formaçaõ de nox em chamas turbulentas sem pré-mistura. Teses de doutorado, Instituto Tecnológico de Aeronáutica, ITA, Brasil., 2003. 